\title{
الفن الشعبي كموروث ثقافي في البيئة العربية وتأثيره على الفن التشكيلي في الصباغة اليدوية
}

\author{
إعلاد \\ / منســ محمد إبر|هيم محمد \\ الأستاذ المساعد بكلية الإقتصاد المنزبي ليحسي

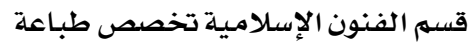 \\ جامعة الملك عبد العزيز- جلدة - المملكة العربية السعودية
}

مجلة بحوث التربية النوعية - جامعة المنصورة

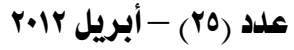




\section{الفن الشعبي كموروث ثقافي في البيئة العربية}

\section{وتأثيره على الفن التشكيلي في الصباغة اليدوية}

إعداد

د/منحممد إبراهيم محمد

\section{: الاll|}

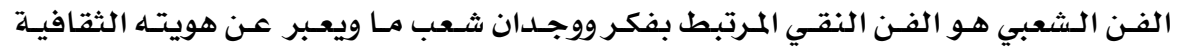

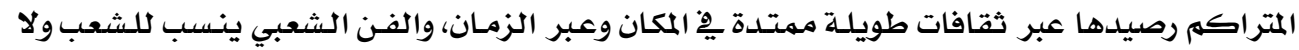

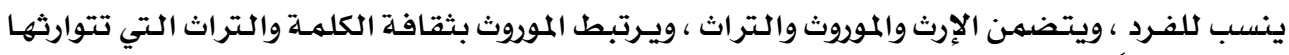
الأجيال جيلاً بعد جيل.

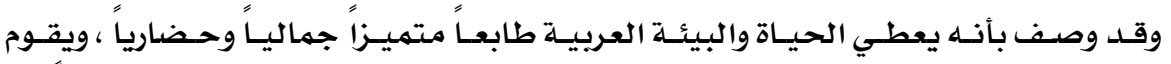

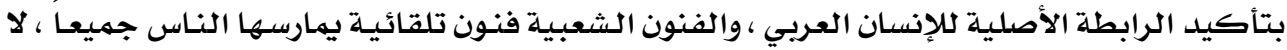

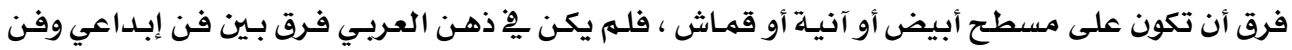

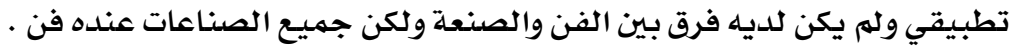

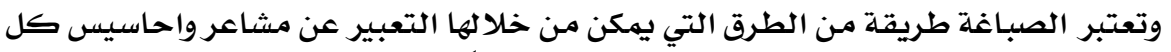

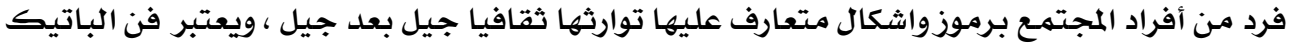

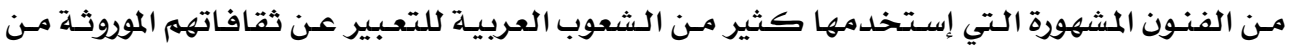

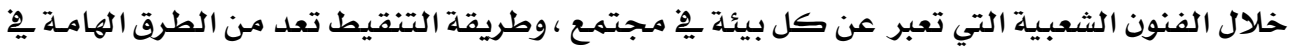

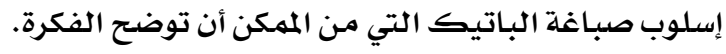

* الأستاذ المساعد بكليـة الإقتصاد المنزبي قسم الفنون الإسلامية تخصص طباعة جامعة الملك عبد العزيز- جدة المملكة العربية السعودية 


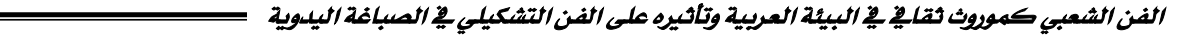 \\ Folk art as a cultural inheritance in the Arab domain And its effect on plastic art in hand-dyeing}

\section{Summary}

Folk art is the pure art related to the conscious and emotions of a certain nation, it reflects its cultural accumulative identity throughout cultures across time and space. Folk art references nations and not individuals. It consists of Heritage and tradition. Tradition per se is related to the culture of the word, and the heritage that is carried out across generations.

It has been described that it provides both life, and the Arabic domain with a distinguished aesthetic style. It heightens the connection of the Arabic individual to his origins. Falk art is an intuitive type of art that is widely practiced; it may be applied on a white canvas, on a piece of fabric, or on the surface of a pot. The understanding of the Arabic mind did not distinguish between creative and applied art, to him there wasn't a significant difference between art and crafts; crafts meant Art to him.

Dyeing is a medium wherein individual's emotions and senses can be reflected through, it is where symbols or common shapes are culturally inherited through generations. Batik is a highly esteemed type of art that has been widely practiced amongst Arabic nations, and through their Falk art inheritance, it portrays concepts such as environment and society.

Dotting with Batik is one of the most prominent dyeing methods that explore the potential of meaning and ideas. 


\section{الفن الشعبي كموروث ثقافي في البيئة العربية}

\section{وتأثيره على الفن التشكيلي في الصباغة اليدوية}

إعداد

د/منحمد إبراهيم/محمد

\section{خالفية البحث:}

الفـن الشعبي هـو الفـن النقـي المـرتبط بفكـر ووجــان شـعب مـا ويعـبر عـن هويتهـ الثقافيـة

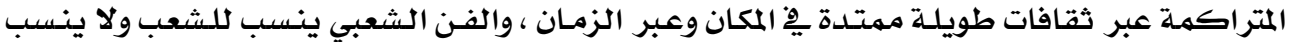

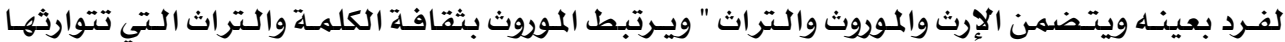

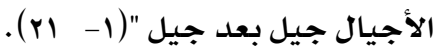

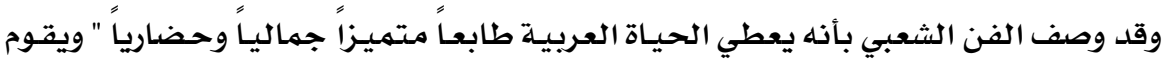

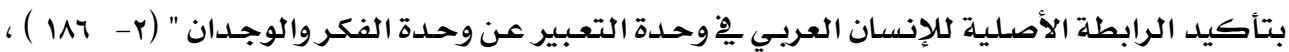

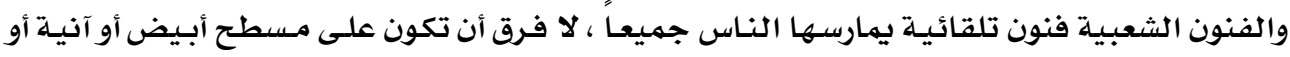

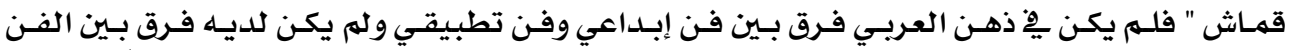

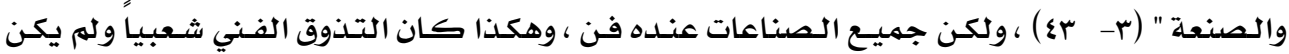

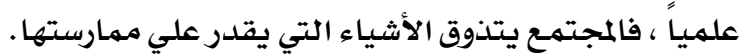

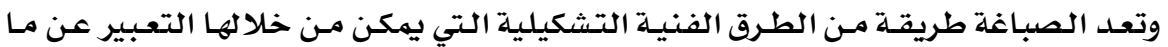

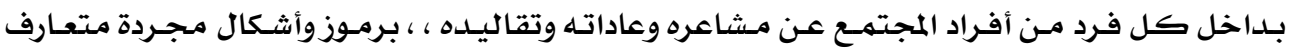

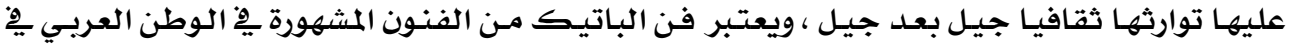

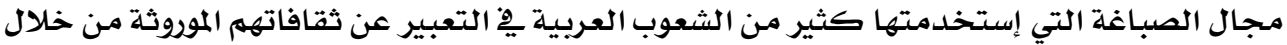

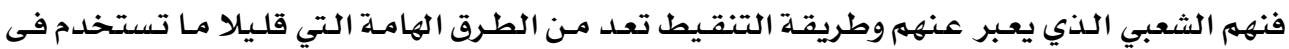
الوطن العربي وخارج الوطن العربي.

\section{هشكلة البحث:}

الفن الشعبي هو الفن المرتبط بفكر ووجدان شعب ويعبر عن هويته الثقافية ، وهي عبارة عن

فنون تلقائية يمارسها ويعبر عن ما بداخله من مشاعر ووعادات وتقاليد من خلال رمـوزوأشكال مجـردة

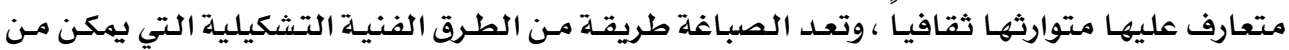

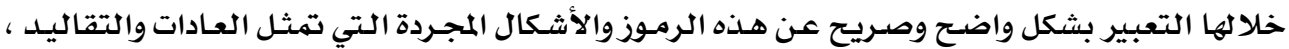

* الأستاذ المساعد بكلية الإقتصاد المنزلي قسم الفنون الإسلامية تخصص طباعة جامعة الملك عبد العزيز- جـدة المملكة العربية السعودية 
كما تعد طريقة صبـاغة البـاتيك بطريقة التنقيط مـن الطرق الهامـة التي قليلاً مـا تستخدم داخل وخارج الوطن بسبب دقتها المتناهية وقد إستخدمتها الباحثة لمحاولة توضع وتأكيد فكرة البحث.

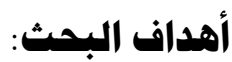

$$
\text { يهدف البحثث إلى: }
$$

• تناول الفن الشعبي كموروث ثقايْ وكقيمة فنية يِّة مجال الصبـاغة اليدوية. • يهكن تطويـع الإمكانـات التشكيلية لأسـلوب صـباغة الباتيـك للتأكيـد على الرمـوزوالأثـكال المجردة داخل الفن الشعبي من خلال طريقة التنقيط.

$$
\begin{aligned}
& \text { • تعتمد تطبيقات البحث على الممارسة الذاتية للباحثة. } \\
& \text { • إستخدام الصبغات الخاصسة بالأقمشة القطنية. } \\
& \text { • إستخدام إسلوب البـاتيك. } \\
& \text { • إستخدام القماث القطن الأبيض. } \\
& \text { • إستخدلام شهـع البر افين ، الإسكندراني ، القلافونية. }
\end{aligned}
$$

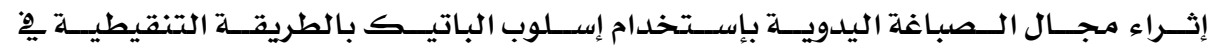
مخرجات مبتكرة.

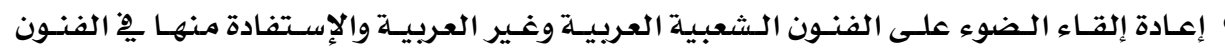
التشكيلية بطرق جديدة فِّ مجال الصبـاغة.

\section{فروض البمث:}

$$
\text { تفترض الباحثة أن: }
$$

ه تناول الفن الشعبي مِ لوحات مصبوغة يدوياً مـن خـلال إسـلوب البـاتيك بـالطريقة التتقيطيـة إضافة تثري القيهم الفنيـة بهـجال التخصص.

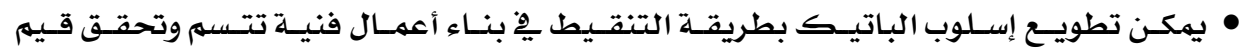
فنية عالية.

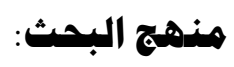

يعتمد البحث على المنهج الوصفي والتجريبي من خلال الإجراءات التالية: 


\section{أولاً الإطار النظري:}

• المقومات الجمالية للفز الشعبي

• الأبعاد الفلسفية للفن الشعبي

• مصادر التعبير وفن الباتيك

• عمل تجارب للتنقيط بطرق مختلفة.

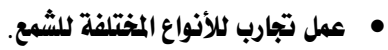

• دراسة لخصائص الفز الشعبي.

• أهمية دراسة الفن الشعبي.

• الألوان المستخدمة في الفن الشعبي.

• دو النقطة في بناء العمل الفني. في الباتيك

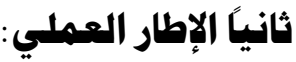

• عمل تجارب لأكثر من طريقة للباتيك لإختيار إحداها.

• عمل تجارب لأنواع أقمشة مختلفة.

أولاً الإطار النظري:

خصائص الثن الشفبي (IIIIII)

يتميز الفن الشعبي بخصائص تميزه عن الفنون الأخرى وتتهثل هذه الخصائص مِِ التالي:

$$
\text { • الوضوح ونسوب لثقافة شعب وليس لثقافة فرد. }
$$

• البعد عن الهيمنة التكوينية على الرهوزوالأثكال.

• بسـاطة اللغة التعبيرية والرهزيـة وثباتها بين الأجيال. • ترجمة مبـاشرة للدلائل الرمـزيـة. • التحديد الخطي للعناصر والرموز.

• سهولة الإدراك الرمزي ووضوحهـ.

• • • إدراك البعد الأيديولوجي والميثودولوجي للإنسـان.

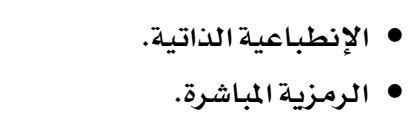

• البعد عن قوانين الآداء والمنظور.

• دلالة اللون المباشر.

• الإهتمام بالألوان الساخنة والتحديدات السوداء.

أهمية دراسة الثن الشعبي

• الوقوف على المكون الحقيقي لثقافة الشعب.

• إدراك العلاقة بين الإنسـان والمكان.

• رصد العوامل المؤثرة يِّ تغير مسارات الشعوب.

المقومات الجمالية للثن الشعبي (ا-1كا)

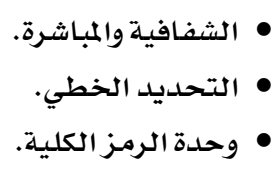

الألوان المستخدمة في الفن الشعبي (ا_17)

يستخدم يخ الفن الشعبي الألكوان المباشـرة والـتي تشير إلىي الهدف مـن إستخدامها ، وتتمثل

هذه الألوان يِّ التالي: 


\begin{tabular}{|c|c|c|}
\hline الدلالة ِِِ المفهوم والثقافة الشعبية & 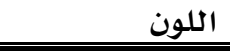 & $\underline{\underline{r}}$ \\
\hline رمز للحجج والصفاء والطهر والفرح والنقاء والعفة. & الأبيض & 1 \\
\hline رمز للدفئ والسعادة والحياة والشروق والحرارة والتلاقي. & الأحمر & r \\
\hline رمز للأمل وإستهـرار الحياة والنهماء والخير الوفير. & الأخضر & $r$ \\
\hline رمز لإتقاء الحسد والنهر والفضاء والسماء والرحاب والسمو. & 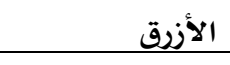 & $\underline{\varepsilon}$ \\
\hline رمزللنضج والأرض والصحراء والسكون. & اصفر & $\circ$ \\
\hline رمز للموت والحدود والنهايات والسكون. & 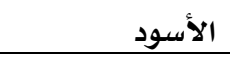 & 1 \\
\hline رمز للصمود والبقاء والتحدي والأرض والنهاية. & 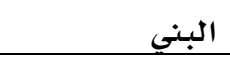 & $\checkmark$ \\
\hline رمز كلأمل والبهجه والسعادة والمرح والوجود والتفائل. & 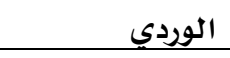 & $\wedge$ \\
\hline الميلاد والوجود والإستمرار والنماء والعطاء. & الأخضر الزرعي & 9 \\
\hline رمز للحزن والفقل والإنهياروالآسى والقهر. & 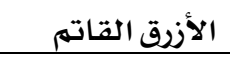 & 1. \\
\hline رم-ز للنضج والغروب والشروق. & البرتقالي & 11 \\
\hline رمز للأبدية والإستقرار والنهاية والظلام. & الإسود القاتم & Ir \\
\hline
\end{tabular}

الأبعاد الفلسفية للفن الشبي

الفـن الشعبي هـو روح الثقافـة الأصلية النقيـة لشعب مـا ، وهو التفكير الفلسفي الـصامت

$$
\text { لميثودولوجيا وأيديولوجيا الشعوب. الشوب. }
$$

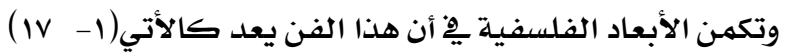

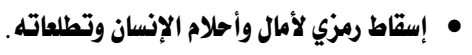

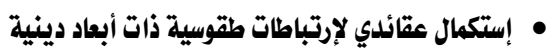

• • وسيط للتنفيس عن الرغبات المكبوتة للإنسان البسيط

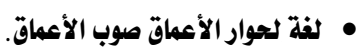
دور النقطة في بناء العمل الفني

تعد النقطة الشكل الأسـاسي للعمل الفني حيث أنها توضـح الفكـرة بطريقـة دقيقة وواضـحة

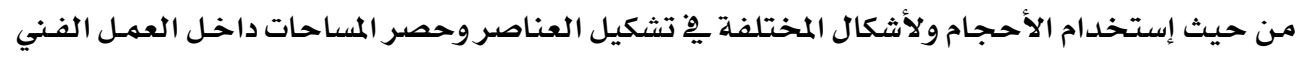

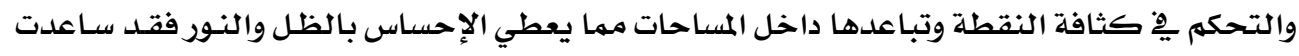




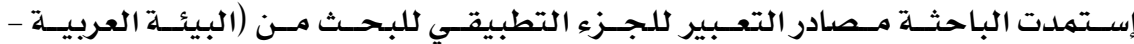

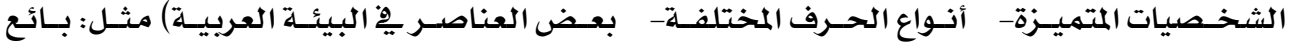

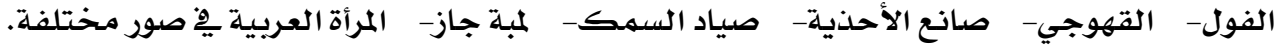

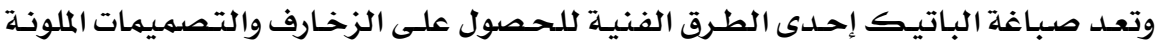

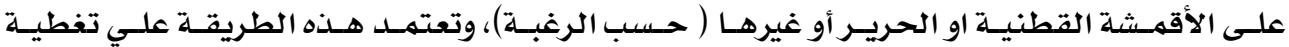

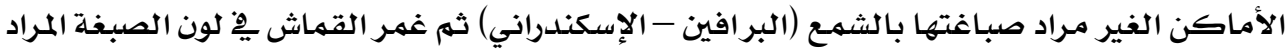

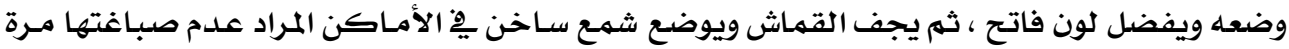

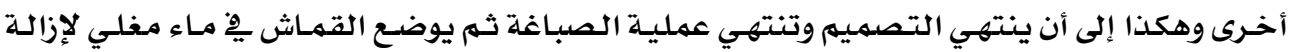

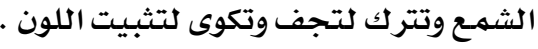

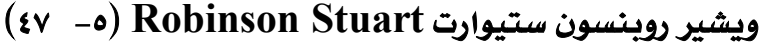

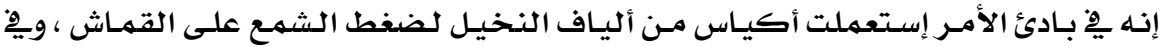

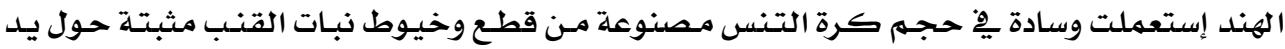

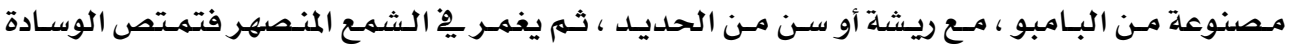
الشمـع المنساب عن طريق الضغط البط علي الوسعادة.

\section{وقد ذكر جاك لينور لارسين vack Leonor Larsen ( - Jack )}

قد يريط إثنان أو أكثر مـن هـذه الأقلام معـا للحصول على خطوط متوازيـة يطلق عليها

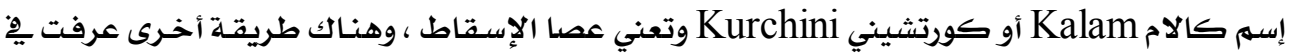

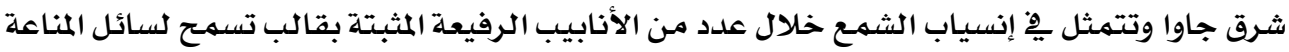

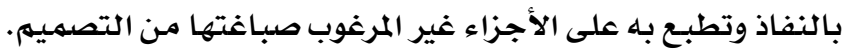

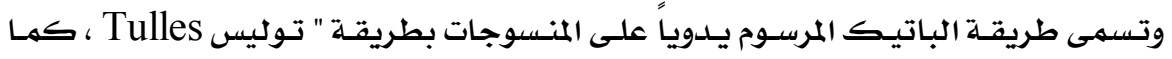

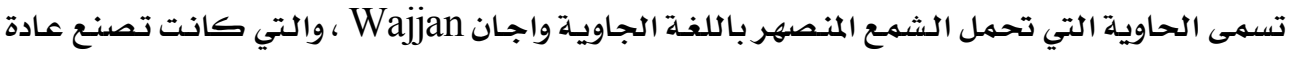

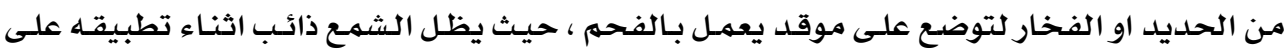
القماش"( - ( - ( )

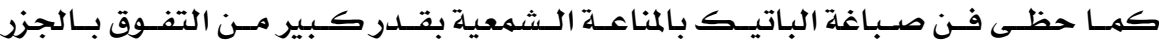

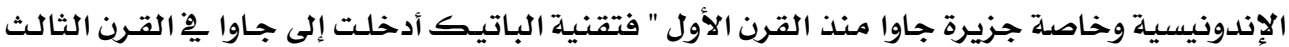

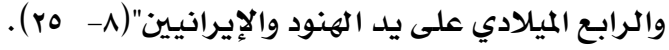
دور النقطة في بناء العمل الثني: يعتمد العهل الفني يِّ هذا البحث على النقطة حيث أنها تقوم على:

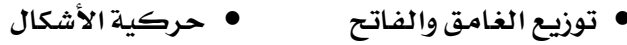

• بناء الشكل • دينامكية النقطة يِّأإتجاه والأبعاد 
القيب الحركية للنظم البنائية للنقطة:

تنشأ القيم الحركية نتيجة لإنطلاق عنصر النقطة من مركز بقوة ، فتأخذ مسار بِّ إتجـاه

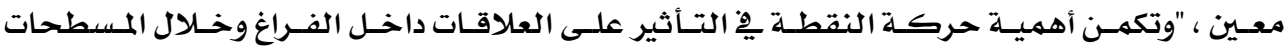

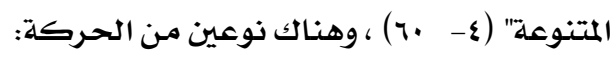

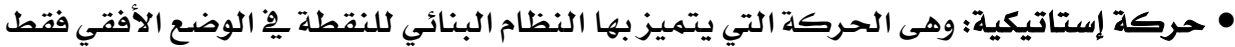

$$
\text { وتتخذ إتجاه اليمين أو اليسار. }
$$

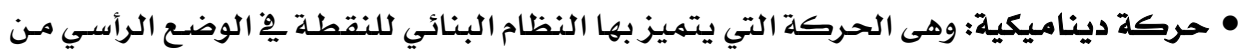

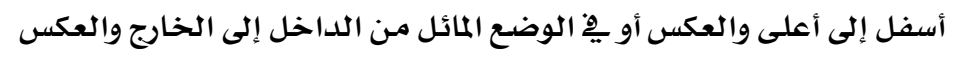

\section{القيم الإيقاعية للنظم البنائية للنقطة:}

الإيقاع هو قيمة تشكيلية تعبر عن " تواصل حركي ناتج عن نظم توزيـع مفـردات تشكيلية

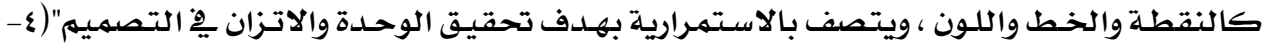

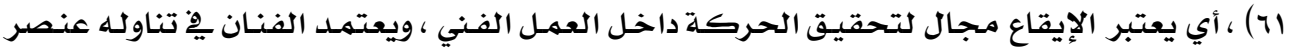

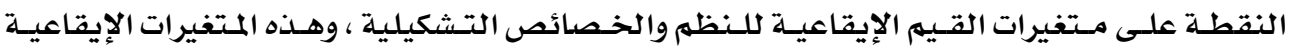

$$
\text { تشتمل على:( }
$$

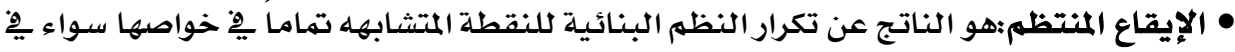

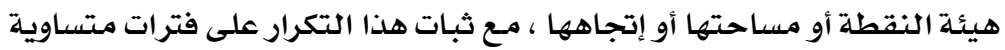

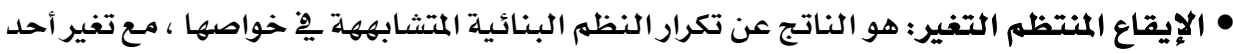

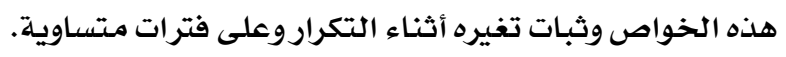

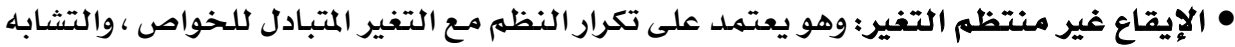

هِِ الفترات.

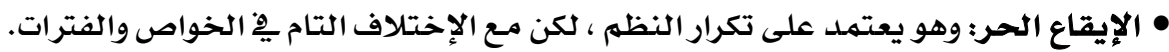

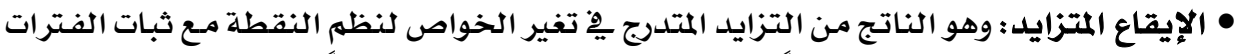

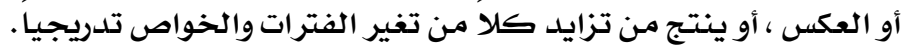

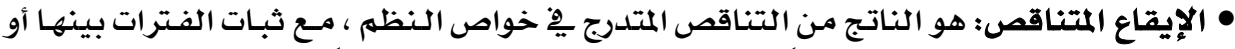

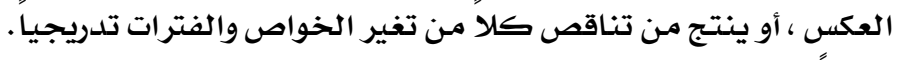

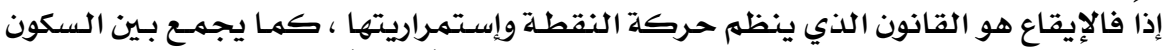

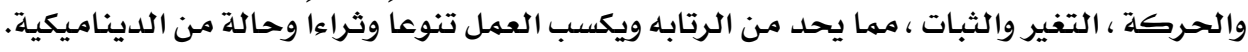

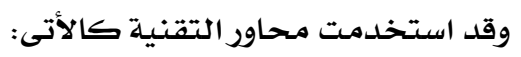

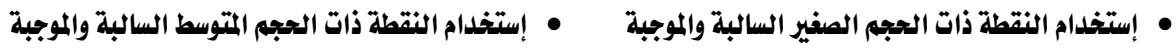

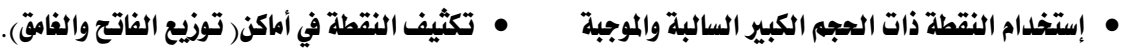
• تماس النقطة وإستخدامها في بناء الشكل الأساسي للعمل الفني.

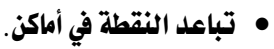
• تحريك النقطة ( إبراز حركة الشكل الساكن). 


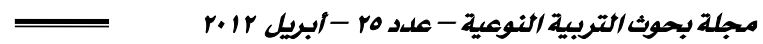

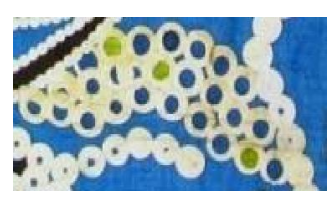

$$
\text { وفيما يلي عرض للتقنيات السابقة: }
$$

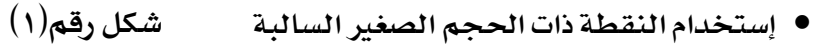

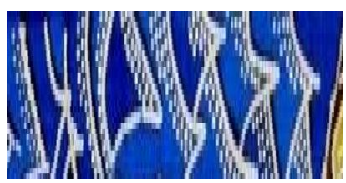

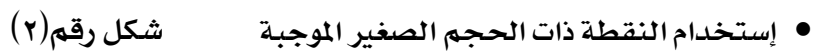

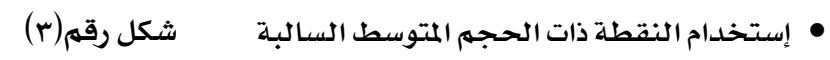

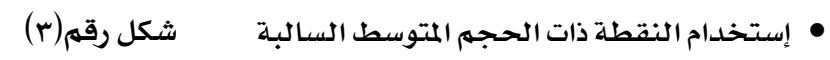
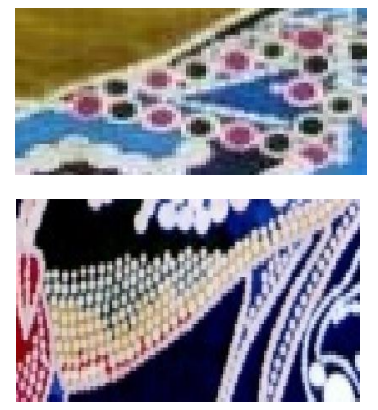

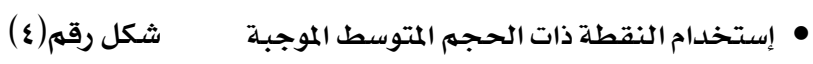

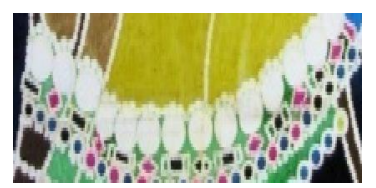

•استخدامض النقطة ذات الحجم الكبيرالموجبة

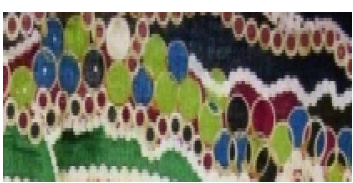

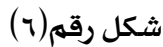

• • • استخدام النقطة ذات الحجم الكبيرالسالبة

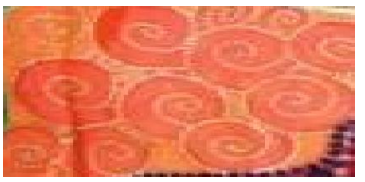

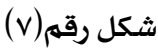

• شكل النقطة ِِ إتجاهات حلزونية دائرية

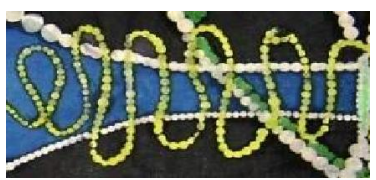

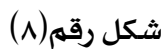

• شكل النقطة ِِّ إتجاهات مموجة

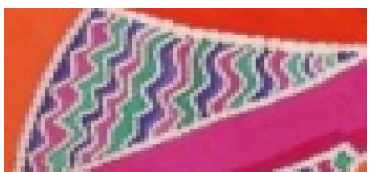

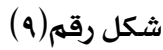

• شكل النقطة يِّ إتجاهات إنسيابية 


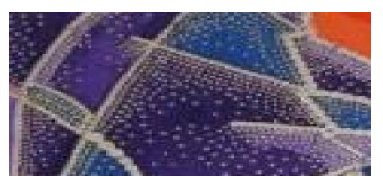

شكل رقم (1.) (1)

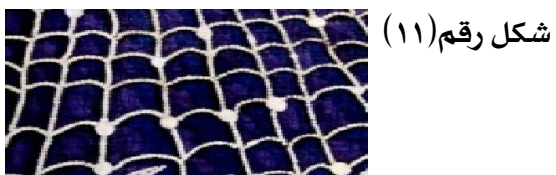

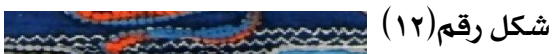
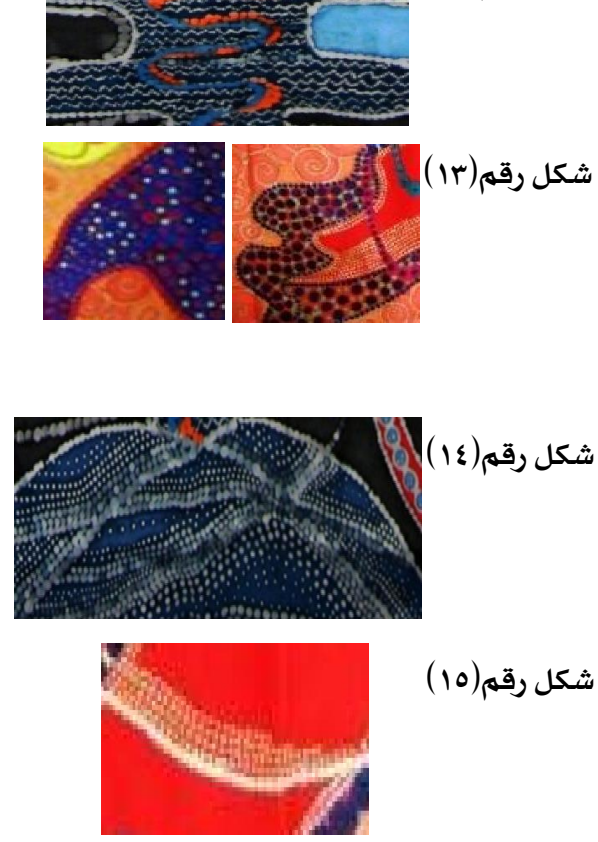

شكل رقم(ع) (1) (1)

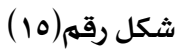

• • (استخدام النقطة على شكل زجزاجي

• شكل النقطة يِ اتجاهات قوسيـ

• شكل النقطة فِ إتجاهات مستقيهة

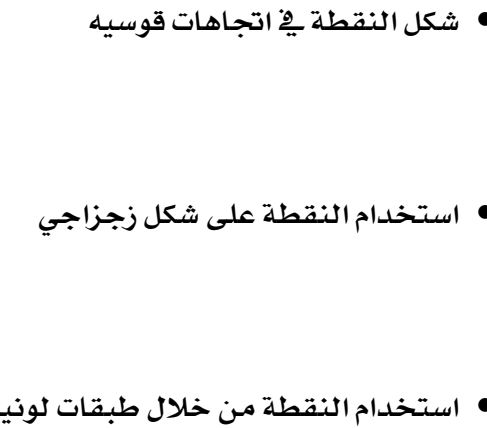

دور النقطة في تكوين الظل والنور

• تباعد النقطة

• تكثيف النقطة

شكل النقطة داخل التكوين

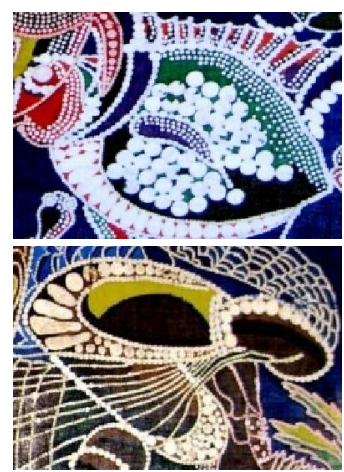

• أحجام وإتجاهات وأشكال للنقطة داخل التكوين شكل رقم(17)

• أحجام وإتجاهات وأشكال للنقطة داخل التكوين شكل رقم(IV) 

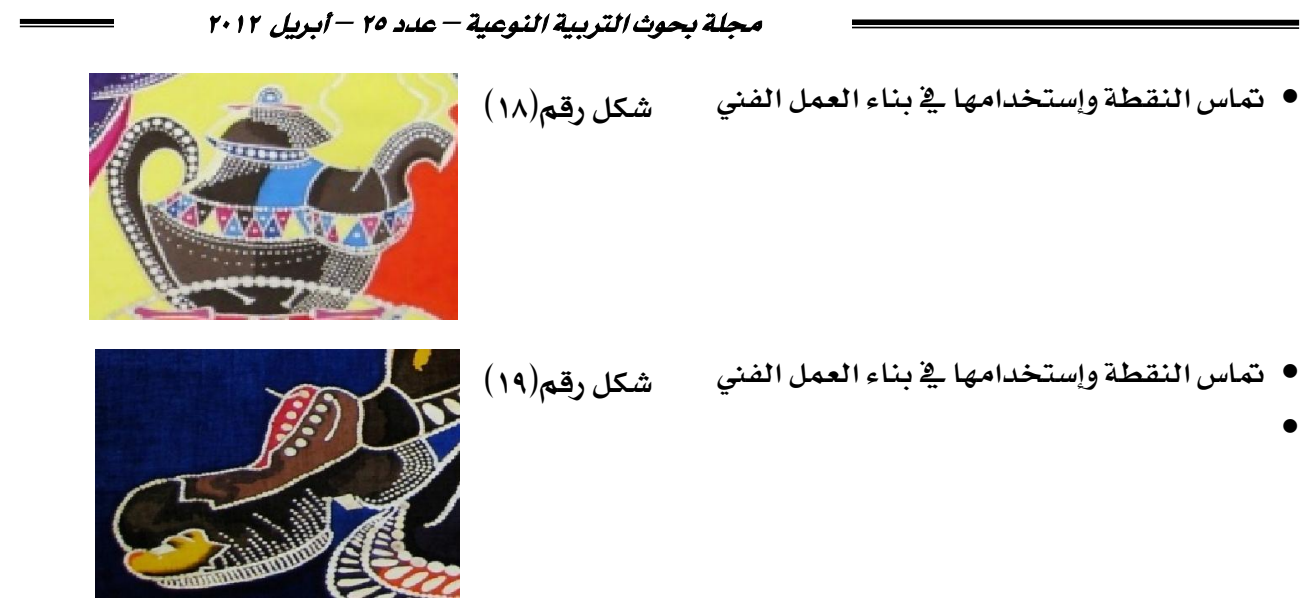

• تماس النقطة وإستخدامها يِ بناء العمل الفني شكل رقم(19)

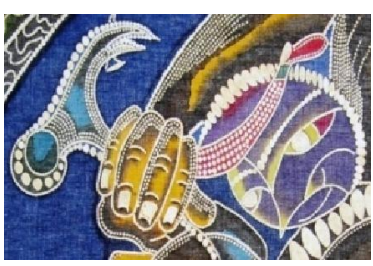

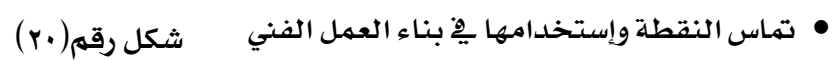

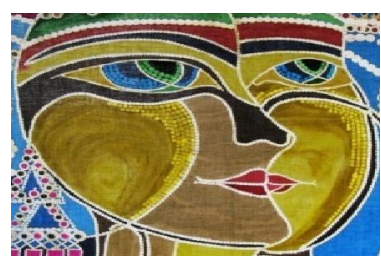

• تماس النقطة وإستخدامها بِِ بناء العمل الفني شكل رقم( )

ومهـا سـبق يتضـح مـــى إمكانيـات التشكيل بـإسـلوب البـاتيـك بطريقـة التنقـيط لـا لها مـن

متغيرات يف الحجم والشكل مكونة صياغات تشكيلية تثري العمل الفني من خلال: • توزيـع الظل والنور بتبـاعد وتقارب النقطة • بناء الشكل من خلال تماس النقطة. • ديناميكية النقطة بِّالإتجاه والأبعاد. • مركية الأثكال.

هدف التجريب:

إنتـاج أعمـال فنيـة قائمــة علـى إسـتثمـار التـشكيل النـاتج مـن إسـلـوب البـاتيـك مــن خـلال تقنية التتقيط. 


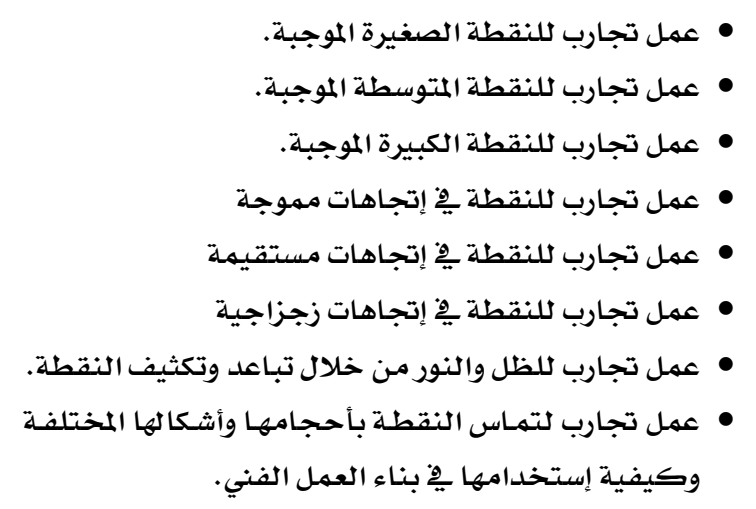

• عمل تجارب للنقطة الصغيرة الموجبة.

• عمل تجارب للنقطة المتوسطة الموجبة.

• عمل تجارب للنقطة الكبيرة الموجبة.

• عمل تجارب للنقطة يْ إتجاهات مموجلة

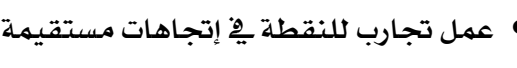

عمل تجارب للنقطة فِ إتجاهات زجزاجية

• عمل تجارب للظل والنور من خلال تباعد وتكثيف النقطة.

وكيفية إستخدامها يخ بناء العمل الفني.

\begin{abstract}
• عمل تجارب للنقطة الصغيرة السـالبـة.
• عمل تجارب للنقطة المتوسطة السـالبـة.

• عمل تجارب للنقطة الكبيرة السـالبـة.
\end{abstract}

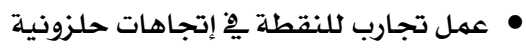

• عمل تجارب للنقطة يِ إتجاهات إنسيابية

• عمل تجارب للنقطة ِِّ إتجاهات قوسية

• عمل تقنيات للطبقات اللونية.

• عمل تجـارب لشكل النقطـة داخل التكـوين

من خلال أحجامها وإتجاهاتها وأشكالها.

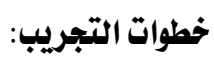

تجربة ذاتية من خلال عمل تصميمات تعتمد على صبـاغة الباتيك بطريقة التنقيط التى

$$
\text { تتسهم بإعطاء قيم فنية عالية يْ تنفيذ أعمال فنية مبتكرة. }
$$

وفيما يلي عرض للأعمال الفنية الخاصة بتطبيقات البحث من عمل الباحثة:

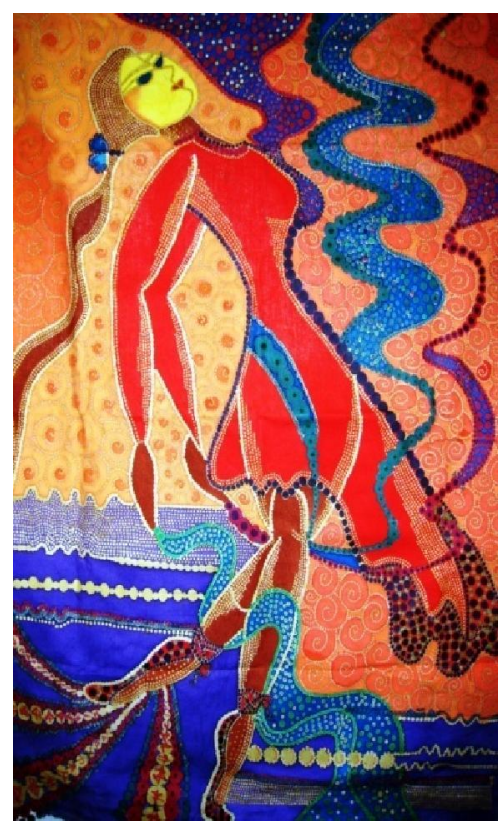

عمل فني رقم (r) (1) (م)

إسه العهل (فتاه وشريط)

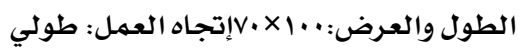

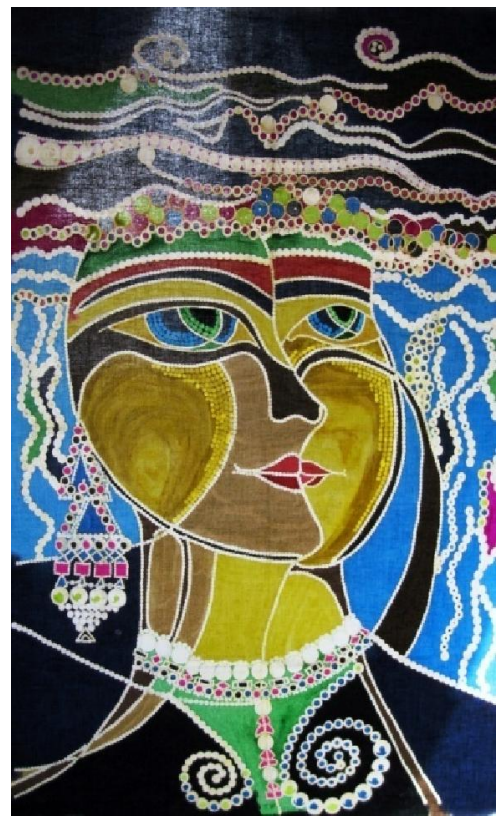

$$
\text { إسمى العمل (وجه فني رقم (1) }
$$

الطول والعرض: . 1 × •vإتجاه العمل: طولي 


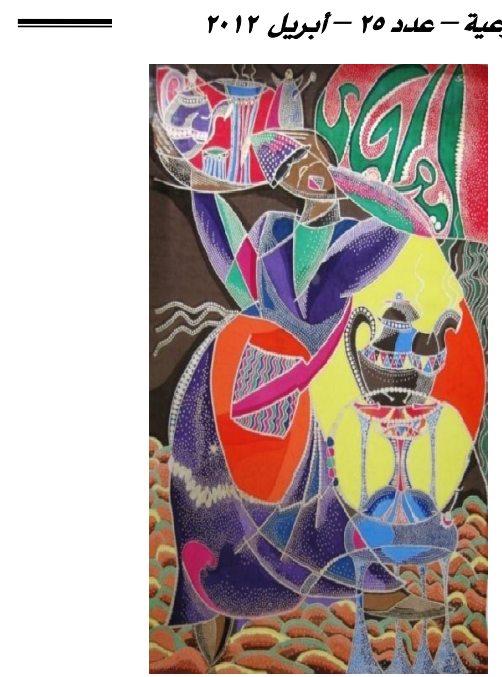

عمل فني رقم (ع)

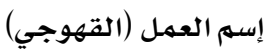

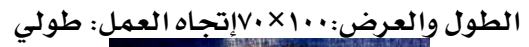

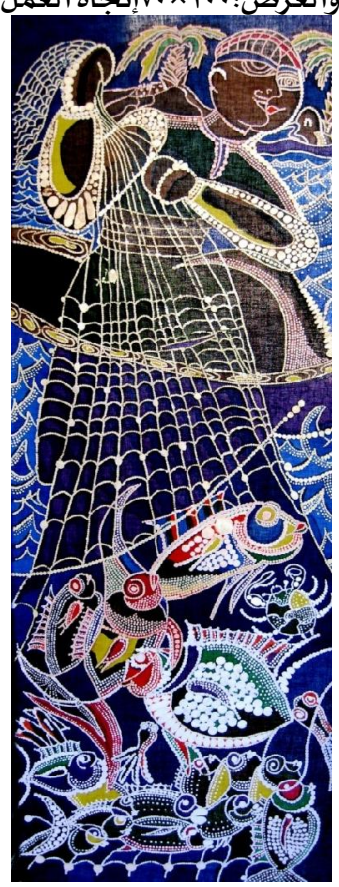

عمل فني رقم (7)

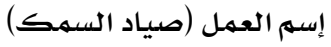

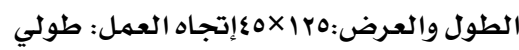

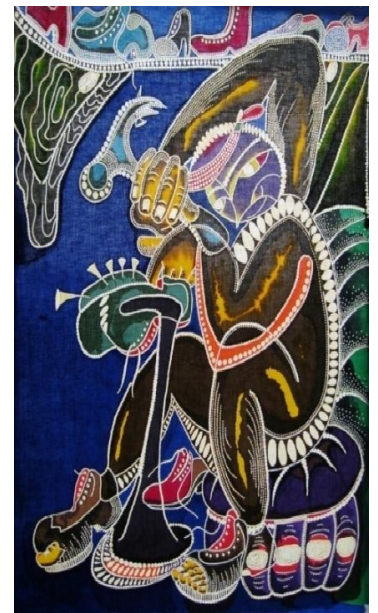

عمل فني رقم (r)

إسهم العمل (صانع الأحذية)

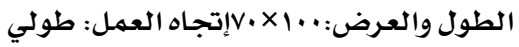

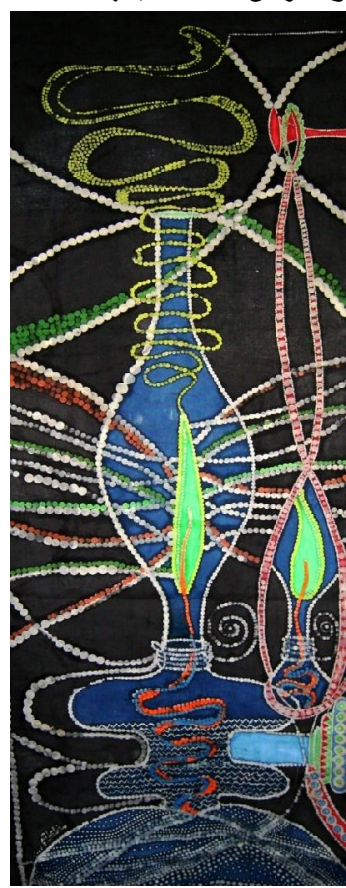

عمل فني رقم (ه)

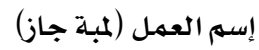

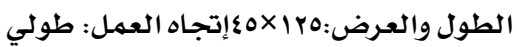




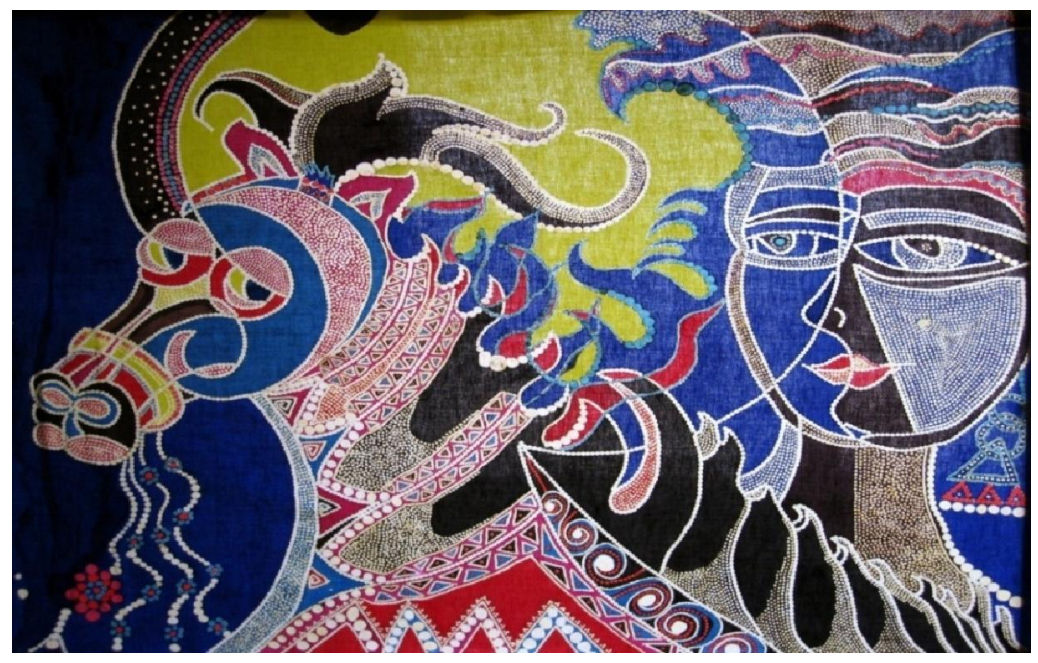

عمل فني رقم (v) إسمى العمل (فتاة وحصان)

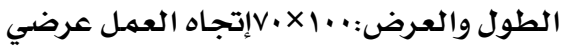

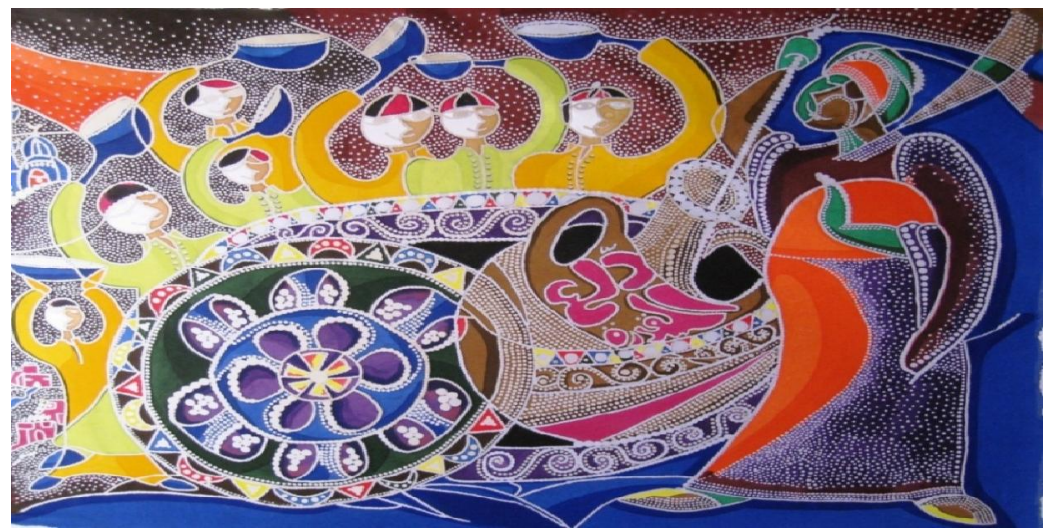

$$
\text { الطمل فني رقم (^) إسم العمل (بائع الفول) }
$$




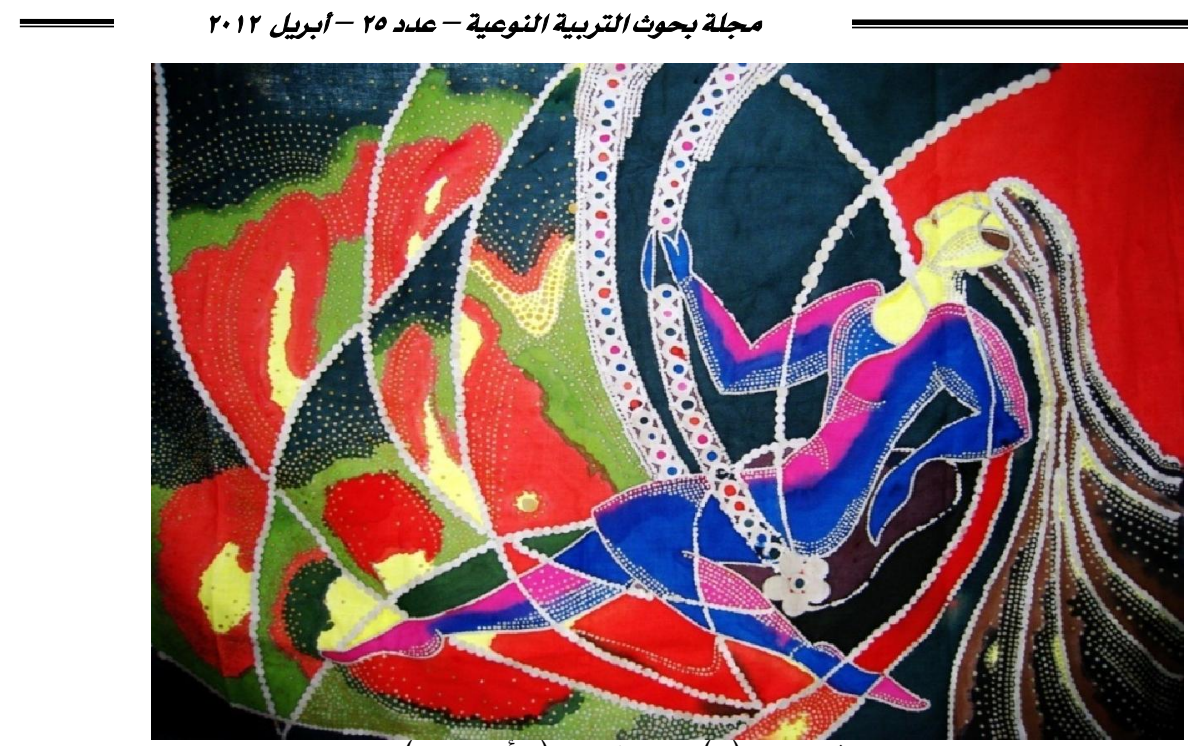

عمل فني رقم (ه) إسم العمل (الأرجوحة)

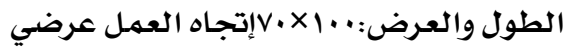

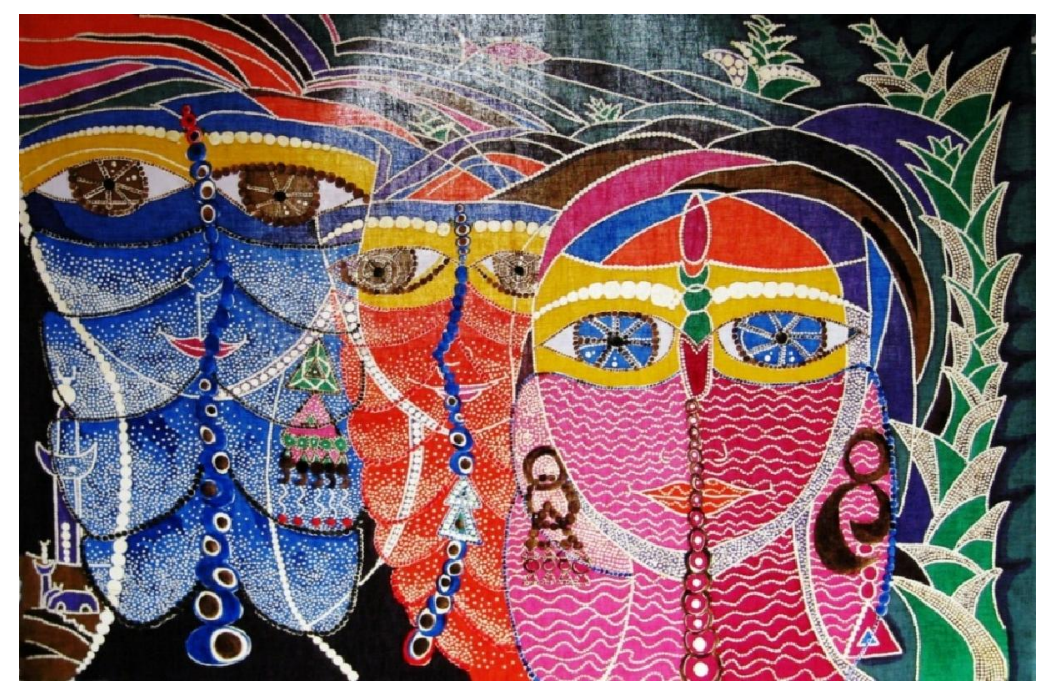

عمل فني رقم ( • 1) إسهم العمل (الثلاث بنات)

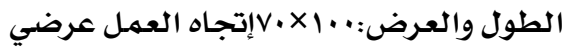


• تحققت قيم فنية عالية من خلال الطريقة التنقيطية للوحات المصبوغة بطريقة الباتيك.

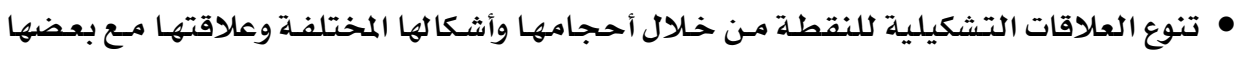

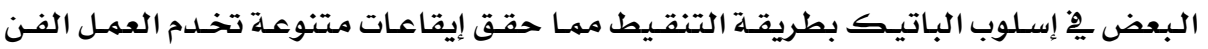

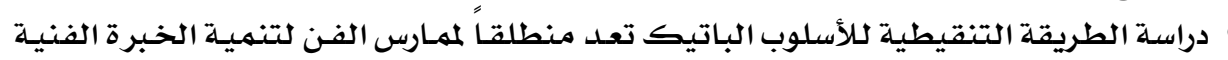

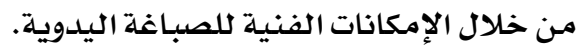

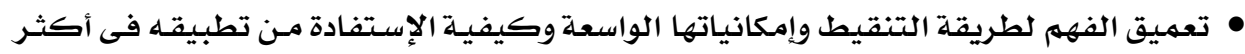
من إسلوب فى مجال الطباعة والصباغة. ثانياً :التوصيات:

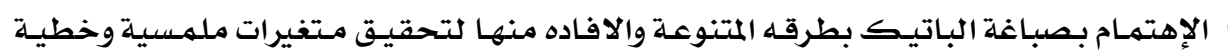

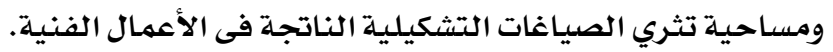

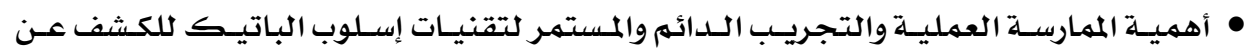

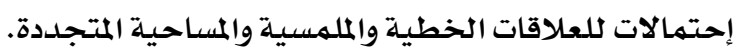

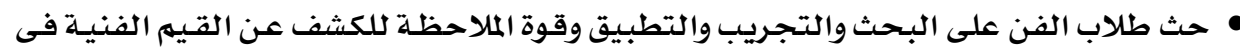

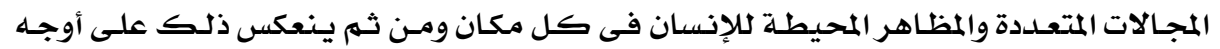
النشاط الفنى.

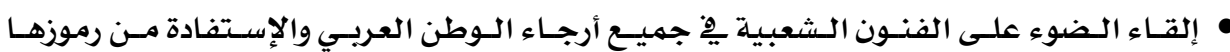

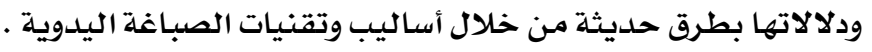

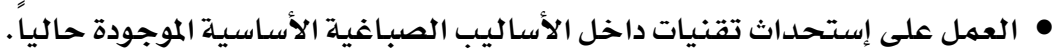




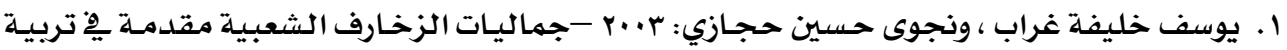

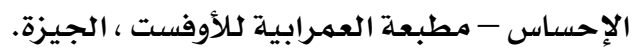

r. صفوت كهمال : 19V7 - مناهج بحث الفولكلور العربي بين الأصالة والمعاصرة - مجلة عالم الفكر. r. أكرم قانصو :r.r.r - التصوير الشعبي العربي r.r دار الجنوب للنشر.

ع. صفاء صـالح محمـد أحمـدئ . ب النظم البنائيسة للخلايا والتفريعات النباتيـة لإثراء التصميمات

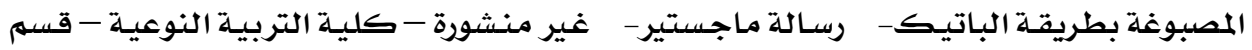
التربية الفنية - جامعة الإسكندرية.

5. Robinson Stuart 1969: History printed Textiles Britain - Studio Vista London -P 47

6. Jack Lenor Larsen 1967 The Dye 'S Art Lkat, Batik, Plangi " - Van No Strand Reinhold - New York - P77

7. http://www.expat.or.id/Batik Traditional Fabric Of Indonesia-P1

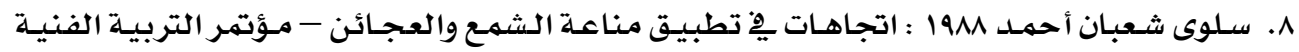

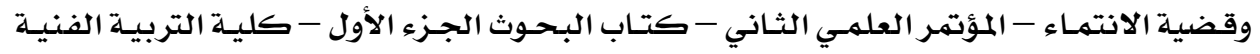
جامعة حلوان 